\title{
INTERCULTURALIDADE E FORMAÇÃO DE LIDERANÇAS INDÍGENAS NA ESCOLA DOM LOURENÇO ZOLLER, COMUNIDADE PEDRA PRETA, RAPOSA SERRA DO SOL
}

\author{
Raimundo Nonato Ferreira do Nascimento (D) $\triangle$
}

Bolsista produtividade CNPq, nível II

Marion Teodósio Quadros (ID $ه$

Universidade Federal de Pernambuco - PPGA/DAM

Vânia Fialho de Paiva e Souza (D ه 
Este artigo objetiva relacionar interculturalidade e formação de lideranças na Escola Dom Lourenzo Zoller e, por meio da etnografia, realçar como essa formação foi sendo apropriada pela comunidade. $\mathrm{O}$ artigo está dividido em três partes. Na primeira, analisamos a escola, desde sua criação nos anos 1970 até os anos 1990; na segunda, seu processo de ressignificação dos anos 1990 à atualidade; e na terceira, a relação entre educação escolar indígena e formação de lideranças. Concluímos que a Escola Dom Lourenço Zoller vem utilizando a interculturalidade como alicerce na formação de lideranças e pelo diálogo de saberes enfrenta as imposições da sociedade nacional promovendo a defesa dos direitos indígenas.

Palavras-chave: Interculturalidade; Educação escolar indígena; Formação de lideranças indígenas

\section{INTERCULTURALITY AND INDIGENOUS LEADERSHIP TRAINING AT LOURENZO ZOLLER SCHOOL IN PEDRA PRETA COMMUNITY, IN RAPOSA SERRA DO SOL}

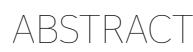

This paper aims to relate interculturality and leadership training at Dom Lourenzo Zoller School and, through ethnography, highlight the way this training was appropriated by the community. The paper is divided into three parts. In the first, we analyze the school, from its creation in the 1990s; in the second, its reframing process from the 1990s to the present day; and in the third, the relationship between indigenous school education and leadership training. We conclude that the school has been using interculturality as a foundation in leadership training, and through dialogue of knowledge, it faces the impositions of the national society promoting the defense of indigenous rights.

\section{Keywords Interculturality; Indigenous school educa-}

tion; Indigenous leadership training.

\section{INTERCULTURALIDAD Y FORMACIÓN DE LIDERAZGO INDÍGENA EN LA ESCUELA DON LOURENÇO ZOLLER DE LA COMUNIDAD DE PEDRA PRETA, EN RAPOSA SERRA DO SOL}

El propósito de este artículo es relacionar la interculturalidad y la formación de liderazgo en la escuela Dom Lourenzo Zoller y, a través de la etnografía, enseñar cómo a comunidad indígena se apropió de esta formación. El artículo está dividido en tres partes. En la primera, analiza la escuela, desde su creación hasta la década de 1990; en la segunda, su proceso de resignificación desde la década de 1990 hasta el presente, en la tercera, la relación entre la educación escolar indígena y la formación de liderazgo. Concluimos que la escuela ha utilizado la interculturalidad como base en la formación de líderes y a través del diálogo del conocimiento enfrenta las imposiciones de la sociedad nacional promoviendo la defensa de los derechos indígenas.

Palabras clave: Interculturalidad, Educación escolar indigena; Formación de liderazgos indígenas. 


\section{INTRODUÇÃo}

Nos últimos anos, no Brasil, temos assistido a um crescente debate sobre os processos de escolarização da educação para os povos indígenas. No entanto, é importante lembrar que a história da educação escolar para essas populações é tão antiga quanto o seu contato com os europeus. Durante os cinco séculos de "colonização" brasileira, a educação escolar e os processos de alfabetização desenvolvidos por missionários jesuítas, carmelitas, salesianos, dentre outros, pela catequese e, em seguida pelo Estado laico, ainda em parceria com as missões religiosas, tinham como propósito a salvação dos indígenas e sua integração à sociedade envolvendo-os por meio da educação escolar (Cohn 2005).

Contra esse ideal salvacionista e integracionista da escola, na década de 1970, iniciam-se projetos alternativos de educação como forma de resistência ao modelo educativo homogeneizante que vinha sendo imposto às comunidades indígenas (Torres 2007, Paladino 2001). Isto, a nosso ver, indica o início de um processo de ressignificação da Escola e da educação escolar por parte dos povos indígenas.

Tal processo deu-se a partir de transformações das políticas indigenistas ocorridas na década de 1970 que tinham como principal objetivo promover uma verdadeira mudança na forma de pensar a educação formal para as populações indígenas
(Paladino 2001). Segundo Silva (2001:10), na última década do século XX, o país viveu o ápice de um movimento iniciado na década de 1970, que tinha como principal objetivo "a transformação das escolas das aldeias, historicamente destinadas à ‘civilização’ dos índios [...] em um lugar do e para o exercício indígena da autonomia”. Esse movimento tinha como principais atores: povos, professores, líderes indígenas e profissionais ligados às ONGs, missionários e universidades. Segundo a autora,

as reivindicações indígenas pelo
reconhecimento de seus direitos
à manutenção de suas formas
específicas de viver e de pensar, de
suas línguas e culturas, de seus modos
próprios de produção, reelaboração
e transmissão de conhecimentos,
uma vez acolhidos pela Constituição
de 1988, abriram caminho para a
oficialização de escolas indígenas
diferenciadas e para a formulação de
políticas públicas que respondessem
aos direitos educacionais dos índios
a uma educação intercultural, bi ou
multilíngue, comunitária e voltada à
autodeterminação de seus povos (Silva
2001: 10).

Foi a partir da Constituição Federal de 1988, que esse "novo" modelo educativo, surgido dos projetos alternativos de educação nas comunidades indígenas, ganhou seu reconhecimento legal e jurídico, além de uma legislação específica, vindo a se configurar como uma política de Estado, denominada de Educação Diferenciada (Cohn 2005) por levar em consideração os conhecimentos próprios das comunidades indígenas e os 
conhecimentos que compõem a base curricular nacional. Nesse novo modelo educativo, a coexistência de dois saberes e, principalmente, a interação entre eles, vem sendo denominado de interculturalidade.

O objetivo deste artigo é evidenciar a relação entre interculturalidade e formação de lideranças na Escola Dom Lourenzo Zoller, realçando como a formação de lideranças foi sendo apropriada e transformada pela comunidade Pedra Preta, a partir das relações com diferentes grupos da sociedade nacional em dois momentos distintos, sendo o primeiro aquele que vai dos anos de 1970 a 1990 e o segundo o que inicia nos anos 1990 e vem até os dias atuais.

É sobre o diálogo de saberes que nos ocupamos neste trabalho. Para tanto, o espaço escolar constitui-se como lócus privilegiado desta análise, pois aí buscamos compreender o processo de ressignificação da escola, que antes servia como instrumento de invisibilização, homogeneização e destituição da cultura para os povos indígenas, agora, tornou-se uma das principais agências de mobilização desses povos em busca do seu reconhecimento. Para tanto, nos pautaremos em dados etnográficos coletados durante pesquisa de campo realizada na comunidade entre os anos de 2011 e 2013, período no qual, pela observação participante, entrevistas, rodas de conversas e grupos de discussão, foi possível observar como professores e demais lideranças indígenas falam sobre a importância da Escola Dom Lourenzo Zoller no processo de formação de novas lideranças na comunidade.

Nesse sentido, constituiu-se um discurso, seja das populações indígenas, de outras agências, ou mesmo de órgãos oficiais, de que a Escola é o local por excelência do "resgate", "revitalização" e valorização cultural, por meio do diálogo intercultural, o que a constitui como um "lugar de fronteiras" (Tassinari 2001). Nela se desenvolvem processos e práticas sociais, que servem como elementos de luta e empoderamento das populações indígenas em busca da consolidação do seu reconhecimento por meio da educação escolar indígena.

Por educação escolar indígena, entendemos o atual modelo educativo que vem sendo oferecido e realizado nessas comunidades. Modelo que, de acordo com a norma constitucional, é diferenciado, intercultural e bilíngue, tendo como base o reconhecimento e o respeito à diversidade étnica e cultural de cada povo (Brasil 1998). Aqui, a noção de interculturalidade que vem sendo utilizada tem como base os pressupostos teóricos apontados por Dietz (2012) e Cortés (2011) que a veem como uma dimensão descritiva da realidade e como uma relação dialógica entre pessoas portadoras 
de culturas e identidades distintas. Ao longo deste artigo, perceberemos como essa noção, coaduna-se com aquela defendida e praticada pelos indígenas em suas relações, seja com as comunidades circunvizinhas seja com o Estado.

O texto está organizado a partir desta introdução na qual apresentamos nosso tema e objetivo. Em seguida, abordaremos a educação escolar na comunidade indígena Pedra Preta a partir da Escola Dom Lourenço Zoller, seu processo de criação e suas atividades entre os anos de 1970 a 1990. Na segunda parte deste artigo, refletiremos sobre o processo de ressignificação da escola na comunidade Pedra Preta a partir da segunda metade dos anos 1990 até os dias atuais. No terceiro e último item convergimos nosso olhar para a relação entre a educação escolar indígena e o processo de formação de lideranças que vem se desenvolvendo desde a década de 1990 nessa escola.

\section{A ESCOLA INDÍGENA DOM LOURENÇO ZOLLER E A EDUCAÇÃO ESCOLAR INDÍGENA ENTRE OS ANOS 1970 A 1990}

Sede da Escola Estadual Indígena Dom Lourenço Zoller, a comunidade Pedra Preta está localizada no extremo Norte do Brasil, a aproximadamente $400 \mathrm{~km}$ da cidade de Boa Vista, capital do estado de Roraima, no município de Uiramutã, interior da Terra Indígena Raposa Serra do Sol.

Fundada em meados da década de 1930, a comunidade recebeu o nome de Pedra Preta, devido a uma grande serra que fica ao seu lado. O local, com aproximadamente 250 metros de altura ${ }^{1}$, é formado por rochas de cor escura dando a impressão de que é uma grande pedra. De acordo com o tuxaua da comunidade, a relação entre o nome da comunidade e a serra deu-se a partir do contato com os não índios. Esses, por não entenderem a língua Macuxi, ao mencionarem a comunidade, faziam referência à serra de rochas negras, como "comunidade da Pedra Preta". Assim, ela passou a ser conhecida com esse nome, em alusão direta à cor das rochas.

$\mathrm{Na}$ época em que a comunidade foi formada, a região ainda não era reconhecida como terra indígena. Naquele período, os indígenas disputavam esse espaço com o gado dos fazendeiros e com os garimpeiros que haviam se estabelecido na região. Essa situação só viria a sofrer uma alteração em meados dos anos 1970, quando se iniciou o processo de reivindicação pelo reconhecimento, demarcação e homologação das terras daquela região como terras indígenas, processo que durou mais de 30 anos e custou a vida de muitos indígenas.

Depois de várias tentativas frustradas de

1 Conforme informações do tuxaua da comunidade. 
promover a demarcação durante as décadas de 1970 e 1980, na década de 1990, finalmente a situação seria "resolvida". A demarcação foi concretizada no ano de 1998, quando da publicação da Portaria de $\mathrm{n}^{\circ}$ 820/98, do Ministério da Justiça. E, em 15 de abril de 2005, o Presidente da República Luiz Inácio Lula da Silva assinou o decreto de homologação da Terra Indígena Raposa Serra do Sol, como sendo de uso exclusivo dos povos indígenas, abrigando, atualmente, cerca 20 mil indígenas, pertencentes aos povos Macuxi, Wapixana, Ingarikó, Patamona e Taurepang.

A comunidade indígena Pedra Preta é hoje constituída por 49 famílias e uma população de 270 habitantes ${ }^{2}$. As famílias são pertencentes aos povos Macuxi e Ingarikó, e com os casamentos entre eles, a maioria pertence ao povo Macuxi. Essa característica também se evidencia em seu sistema linguístico, pois são falados cotidianamente três idiomas na comunidade: o macuxi, o ingarikó e o português, com predominância do último.

A presença dos Ingarikó na comunidade é recente. De acordo com o tuxaua, que é Macuxi, a chegada dos Ingarikó, deu-se precisamente a partir do ano de 2006. Apesar de viverem na mesma comunidade, dividirem os mesmos espaços e até alguns casamentos interétnicos, os processos de interação entre os Ingarikó e
Macuxi ainda são muito tímidos. Essa situação é relatada pelas lideranças da comunidade e por nós constatada durante o trabalho de campo, acontecendo, principalmente, por causa do sistema linguístico. Apesar de pertencerem ao mesmo tronco linguístico - Caribe -, apresentam variações em suas línguas, o que dificulta o processo comunicativo. Ademais, os Ingarikó mantêm seu próprio idioma como língua materna, assim, $100 \%$ dos que vivem na comunidade, desde as crianças até os adultos, são falantes da sua língua materna. É válido ressaltar que entre os mais velhos e alguns jovens há aqueles que, além da língua materna, também dominam o português. Já entre os Macuxi, a situação é diferente: apesar de haver um esforço, como veremos adiante, para uma retomada do uso da língua materna, apenas os mais velhos, cerca de $10 \%$ da comunidade, falam a língua Macuxi, bem como o português. Dessa forma, para eles, a língua portuguesa acaba funcionando como primeira língua, ou seja, a língua materna. Essa situação acaba por interferir nos processos comunicativos/interativos entre os Macuxi e os Ingarikó, sobretudo na Escola, pois a maioria dos professores fala apenas o português, dificultando o estabelecimento de uma comunicação e interação com os alunos da etnia Ingarikó.

2 Dados fornecidos pelo tuxaua da comunidade no mês de abril de 2013. 
O sistema de educação escolar da comunidade Pedra Preta data do início dos anos 1970 e surge como uma necessidade da comunidade: lutar contra um sistema de exploração que há muito se instalara na região, como nos evidenciou o professor indígena Getúlio. De acordo com as lideranças da comunidade, naquele período, existia uma grande exploração dos indígenas por parte de garimpeiros e fazendeiros. Tal exploração davase em virtude do analfabetismo dos indígenas, pois como eles não sabiam ler nem escrever, os garimpeiros e fazendeiros aproveitavam para lhes roubar aquilo que eles possuíam. Frente a essa situação de exploração instalada na região, o tuxaua da comunidade à época, preocupado com as repercussões desse problema para o futuro das crianças e jovens, passou a reivindicar junto às autoridades competentes, uma escola para a comunidade, cujo principal objetivo era preparálos para defenderem-se contra a ação predatória de garimpeiros e fazendeiros que moravam na região.

No ano de 1971, como resultado destas reivindicações, foi implantado o sistema de educação escolar de $1^{\mathrm{a}}$ a $4^{\mathrm{a}}$ série na comunidade. Os moradores mais idosos afirmavam que a escola havia chegado com o seguinte objetivo: "ensinar as crianças a ler e escrever para serem civilizados”.

A afirmação acima é importante, e tem grande significado, pois não somente os indígenas, mas principalmente a população não indígena daquela região, acreditava que ser civilizado era saber ler e escrever. Tomando essa crença como base, entendemos as afirmações desses idosos, pois quando crianças e jovens soubessem ler e escrever, estariam, portanto, aptos a lutar para não serem explorados por fazendeiros e posseiros. É importante lembrar que, historicamente, essa foi a ideia disseminada para os povos indígenas desde o período colonial. Durante a "colonização" do Brasil, a escola, o trabalho e a religião foram vistas como instituições que, juntas, seriam capazes de promover a "civilização" dos povos "selvagens". Foram esses, portanto, os meios mais eficazes encontrados pela Igreja para promover tal processo. Nesse sentido, os índios seriam civilizados a partir do momento em que soubessem ler e escrever, sendo esse o sentido da educação escolar para os povos indígenas até a década de 1970.

A partir dessa década, a Igreja Católica no Brasil, influenciada pelo Concílio Vaticano II, incorporou uma nova forma de evangelizar, e sua ação pastoral junto aos povos e comunidades indígenas passou a ser a implantação de escolas, cujo intuito era formar lideranças para atuarem contra o sistema de exploração desencadeado por garimpeiros e fazendeiros ${ }^{3}$. Seguindo esse novo

3 Sobre o processo de implantação de escolas nas comunidades indígenas em Roraima, ver Nascimento (2014). 
ímpeto missionário, a Igreja em Roraima fez uma opção preferencial pelo trabalho com os povos indígenas naquela região. Foi, portanto, neste contexto que houve a implantação da escola na comunidade Pedra Preta, tendo a dupla função de "civilizá-los", por meio da leitura e escrita, e formar lideranças comunitárias para atuarem com as mesmas "armas" contra a exploração causada por garimpeiros e fazendeiros.

Não se trata de uma ação isolada, Rebolledo (2009), ao refletir sobre os processos de escolarização dos Palikur, no Amapá, também demonstra que ali os povos indígenas tinham a mesma ideia da Escola: de ensinar os índios a ler e escrever, pois a partir daquele momento, os debates e lutas por direitos passariam a ocorrer pela escrita.

Para a implantação da escola em Pedra Preta, o tuxaua da época teve como aliado em suas reivindicações os missionários da Consolata, por meio da missão religiosa São José do Surumu ${ }^{4}$, já que eles faziam o trabalho de expansão da educação escolar para as comunidades indígenas daquela região. Naquela época, a Escola da Missão do Surumu servia como um centro irradiador da educação escolarizada e havia começado um trabalho de formação de professores indígenas para atender as comunidades da região.

É, portanto, seguindo essa lógica da Missão do Surumu, que foi criada a escola na comunidade Pedra Preta, inaugurada pela maior autoridade eclesiástica do estado - o Bispo de Roraima à época, Dom Servílio Conti, e outras autoridades eclesiásticas e civis. Ainda como forma de agradecimento aos religiosos, a escola recebeu o nome de Dom Lourenço Zoller5.

O assim chamado processo de "civilização" dos indígenas tinha como fundamento a formação de lideranças que pudessem lutar contra categorias específicas desse grande grupo que falava e escrevia em português, os fazendeiros e garimpeiros. Interessante notar que a Igreja Católica, um agente que atuava diretamente contra a valorização da identidade indígena, percebe, então, por meio dos missionários da Consolata, que precisava aliar-se aos povos indígenas na luta pela conquista de suas terras e, consequentemente, no processo de reconhecimento de sua identidade étnica. O fato de a missão acima citada ter se "aliado" aos indígenas, não pode ser visto como uma ação de benevolência, é preciso analisar os interesses que estavam por trás desse processo de construção de alianças. O

4 Esta missão foi criada no início do século XX, por missionários beneditinos e passada aos missionários da Consolata no final dos anos 1940. Esses últimos transformaram o internato da missão em uma escola de formação de professores, exatamente para prover as comunidades daquela região.

5 Monge beneditino e terceiro bispo prelado da Prelazia de Nossa Senhora do Carmo, atual Diocese de Roraima. 
certo é que, naquele momento, tal apoio foi de fundamental importância para os povos indígenas, pois viviam em situação de permanente ameaça representada por garimpeiros e fazendeiros.

A perspicácia dos indígenas da região em se aliar aos missionários a fim de conseguir fazer frente a outros dois grupos cuja ameaça era mais forte, mostra o processo de luta dos povos indígenas e sua capacidade de leitura da sociedade nacional como constituída por vários grupos de interesses diversificados. Tal situação evidencia uma prática intercultural na qual avaliam a existência de aliados e inimigos que falam o português e constroem alianças como forma de empoderamento para enfrentamento dos grupos ameaçadores.

A formação de professores como lideranças indígenas é uma expressão de estratégia fundamental para esses grupos. Aqui, mais uma vez, é possível perceber que a estratégia de formação de lideranças é priorizada pela missão e incorporada pelos grupos. Dessa maneira, a formação de lideranças, em si, é uma prática intercultural, pois nasceu da necessidade dos povos indígenas se relacionarem de modo menos desigual com a sociedade nacional.

Com o intuito de ajudar a suprir a demanda de professores indígenas nas comunidades, os missionários da Consolata, por meio da escola da
Missão São José do Surumu, realizavam, desde o início dos anos 1970, um trabalho de formação de lideranças comunitárias, tendo como base a Teologia da Libertação, além de atuarem no processo de formação de professores.

Na escola da missão, os jovens indígenas que ali chegavam, eram preparados para ter uma profissão e para serem líderes comunitários. É importante ressaltar que a maioria das lideranças indígenas de Roraima que atuou no processo de luta pelo reconhecimento e demarcação da Terra Indígena Raposa Serra do Sol, estudou na Escola do Surumu. Formadas as primeiras turmas de professores, outra escola foi criada com a mesma perspectiva na comunidade Maturuca e torna-se também um centro de formação, atendendo a uma grande quantidade de jovens das mais diversas comunidades da região.

Entretanto, esse ideário da missão não se irradiou para todas as escolas indígenas ao mesmo tempo, pois a capacidade de absorver os jovens para a profissionalização e, especialmente para a formação de professores ainda era muito pequena. Também convergiu para isso a necessidade dos pais ou da comunidade darem uma contrapartida de ajuda na manutenção da escola, o que nem sempre era realizado. Essa situação, muitas vezes, fazia com que o aluno abandonasse a escola e voltasse para a comunidade. 
O que se percebe, frente ao exposto, é que a partir dos anos 1970, foram coexistindo dois modelos educativos nas comunidades indígenas. De um lado, um modelo baseado nos ideais de autodeterminação dos povos, a partir da valorização da diversidade e sob a responsabilidade de professores indígenas e, por outro lado, as escolas para indígenas, como foi o caso da Dom Lourenço Zoller, que apesar de ter nascido das exigências da comunidade, atuava a partir do viés homogeneizante e com professores não indígenas.

Com a inauguração, veio também a imposição de novos costumes, como a religião e a língua portuguesa. Nos primeiros anos de funcionamento, os indígenas foram proibidos de utilizar a língua, sendo obrigados a aprender o português. Essa prática não foi um "privilégio" da comunidade Pedra Preta, acontecendo em outras regiões onde o intuito da escola sempre foi o mesmo: a homogeneização cultural das populações indígenas. Dessa forma, o dizer dos mais antigos da comunidade parecia se concretizar, pois os indígenas daquela localidade agora estavam sendo "civilizados", já não falavam mais na língua materna, mas o português, língua oficial da nação e símbolo da civilização.

\footnotetext{
"Quando eu estudei tinha uma diferença pela seguinte forma, porque na escola antes tinha uma regra muito crítica, então você tinha que estudar mesmo, por exemplo, o professor
}

dava matemática, ciência, geografia, história, e o português, não tinha Macuxi. Então eu tinha que estudar matemática, tinha que estudar ciência porque na matemática era uma coisa principal e o português. Então tinha que estudar e naquele tempo era a lei da palmatória, então pra mim [sic] não pegar palmatória eu tinha que estudar matemática [...]. O Macuxi na escola era proibido. Porque eles tinham que ensinar só o português, né? Quer dizer, assim, nunca chegou a me proibir, né? Mas, na verdade, a gente pretendia falar mais não conseguia, porque nenhum professor entendia [...], a gente falava com a mãe e com outras pessoas." (Tuxaua da comunidade, entrevista realizada em abril de 2013, grifo nosso).

É importante mencionar que mesmo tendo sido fundada no ano de 1971, a escola só foi reconhecida como uma instituição escolar de $1^{\mathrm{a}}$ a $4^{\mathrm{a}}$ série (atual Ensino Fundamental I), no ano de 1977, por meio de um decreto do governo do então Território de Roraima (Decreto $\mathrm{n}^{\circ} 27$, do dia 24 de agosto de 1977). De acordo com o tuxaua da comunidade, naquele período, cerca de $90 \%$ da população da comunidade era monolíngue em Macuxi. Hoje, 40 anos após a instalação da escola na comunidade, a situação é inversa: menos de $10 \%$ da população da comunidade continua falando a língua.

Durante seus primeiros 20 anos de existência, a Escola Dom Lourenço Zoller passou por muitas dificuldades, especialmente a falta de professores, pois sendo eles não indígenas, não se adaptavam à vida na comunidade e, como consequência, em um pequeno espaço de tempo a deixavam. Tal 
situação ainda é uma constante nas comunidades indígenas.

É importante destacar que entre os anos de 1970 a 1990, os processos de formação de lideranças estavam concentrados na Escola da Missão São José do Surumu e na escola da comunidade do Maturuca. Elas podem ser vistas como sendo centros de formação de onde saíam os professores para atuar nas diversas comunidades da região. À medida em que essas duas escolas iam formando jovens indígenas para serem professores e lideranças, eles voltavam para suas comunidades, iniciando um processo de ressignificação da escola e da educação escolar. É, portanto, sobre esse processo que vamos falar, tomando como base a Escola Dom Lourenço Zoller.

\section{PROCESSO DE RESSIGNIFICAÇÃO DA ESCOLA E A FORMAÇÃO DE LIDERANÇAS NA COMUNIDADE PEDRA PRETA}

No ano de 2013, época da pesquisa de campo, a Escola Dom Lourenço Zoller contava com uma clientela de 148 alunos da Educação Básica, divididos em duas modalidades: a modalidade regular, com o Ensino Fundamental de $1^{\circ}$ ao $9^{\circ}$ ano e a Educação de Jovens e Adultos (EJA) segundo e terceiro segmentos. Para atender a essa demanda, a escola contava com um corpo docente formado por 13 professores, todos indígenas.

A escola ainda não contava com uma proposta pedagógica escrita, no entanto, vinha trabalhando de acordo com os desejos da comunidade, cujo intuito maior era formar os alunos para que pudessem contribuir com os trabalhos da comunidade e, sobretudo, formar lideranças comunitárias. Nesse sentido, de acordo com a coordenadora pedagógica, a escola vinha desenvolvendo junto à comunidade uma educação diferenciada específica, bilíngue e intercultural.

Como vimos linhas acima, a educação escolar na comunidade indígena Pedra Preta, data do início da década de 1970; no entanto, os primeiros passos rumo a uma educação específica e diferenciada somente seriam dados na primeira metade da década de 1990, especificamente no ano de 1994. Até aquele momento, na escola, não havia uma preocupação com o ensino da língua e valorização da própria cultura. Somente a partir daquele ano, 1994, inicia-se a preocupação com uma educação mais voltada à valorização da cultura e à formação cidadã, ação que se prolonga até os dias atuais, tendo como uma de suas bases, a formação de lideranças comunitárias.

6 A Educação de Jovens e Adultos está dividida em três segmentos: o primeiro abrange o ensino de $1^{\circ}$ ao $5^{\circ}$ ano, que corresponde ao Ensino Fundamental I; o segundo abrange o ensino do $5^{\circ}$ ao $9^{\circ}$ ano, que corresponde ao Ensino Fundamental II; e o terceiro abrange o Ensino Médio, completando assim, o ciclo da Educação Básica. 
De acordo com Mara, professora indígena da etnia Macuxi, a década de 1990 foi de fundamental importância para uma transformação da educação escolar na comunidade. Foi exatamente no ano de 1994, a primeira vez que a escola se envolveu em ações relacionadas à valorização cultural. Até aquele momento, ela não se diferenciava das demais não indígenas. No entanto, por meio do diálogo entre alunos e professores de outras escolas, a exemplo da Escola do Maturuca e a Escola do Surumu, a Escola Dom Lourenço Zoller passou a realizar ações voltadas ao reconhecimento e valorização da cultura indígena.

Conforme o relato da professora Mara, a ação tida como marco fundante da valorização cultural na comunidade e, consequentemente, do início da transformação do modelo educativo homogeneizante, em um novo modelo, que valoriza e respeita a cultura da comunidade, foi uma atividade desenvolvida pelos alunos para recepcionar o Bispo de Roraima em visita pastoral à comunidade. Tal atividade consistia em cantar uma música de boas-vindas, na língua Macuxi, além de dançar um parixara ${ }^{7}$ - símbolo da cultura tradicional do povo Macuxi, elemento demarcador da "fronteira étnica", bem como um dos principais aspectos de sua "distintividade cultural" (Barth 2000: 89). Essa iniciativa partiu da jovem Mara, à época, aluna da escola do Centro Regional Maturuca e familiarizada com esse tipo de ação.

Segundo a professora, após essa recepção, o bispo procurou as lideranças para parabenizálas pela bonita acolhida, chamando a atenção, principalmente, do professor, para que aquele trabalho continuasse. Assim, Mara (hoje professora) lembra que, a partir de uma simples ação, a escola deixava de ser vista como um elemento de homogeneização e passava a ser uma das protagonistas da mudança e do processo de valorização cultural do povo Macuxi. Nesse acontecimento, podemos perceber a importância das escolas de formação de lideranças, nesse caso, a Escola do Maturuca.

Além deste importante passo rumo à transformação do fazer educacional, nos anos seguintes, a Escola Dom Lourenço Zoller passou por outras mudanças significativas. No final da década de 1990, ela foi finalmente reconhecida como de $1^{\circ}$ grau completo (atualmente Ensino Fundamental completo). Esse reconhecimento, assim como a expansão do ensino até a $8^{\mathrm{a}}$ série (atual $9^{\circ}$ ano), segundo o professor Getúlio, veio atender a uma demanda, não somente da

7 O parixara é um dos ritos tradicionais dos povos Macuxi, Wapixana e Ingarikó e é dançado na celebração da colheita ou por ocasião de eventos festivos. 
comunidade Pedra Preta, mas também de várias comunidades da região.

Naquele período, as lideranças das comunidades viram que grande parte da juventude estava se "perdendo", devido à influência de aproximadamente 15 mil garimpeiros que haviam se instalado na região. Com eles, vieram também a bebida alcoólica, a malária e outros males. Como a escola ainda não oferecia o Ensino Fundamental completo, muitos jovens em idade escolar, que não conseguiam vaga na Escola do Centro Regional Maturuca ou mesmo na Escola do Surumu, estavam indo trabalhar com os garimpeiros, causando problemas para as comunidades.

Aqui, mais uma vez, vemos a importância que a instituição educacional adquiriu dentro daquela comunidade indígena. Ela, que antes era vista como sinônimo de homogeneização e imposição da cultura nacional, passava agora a ser vista como um elemento importante de valorização da cultura da comunidade, mas também como a possibilidade de tirar a juventude das situações de marginalidade causadas pela presença dos fazendeiros e garimpeiros naquela região. Dessa forma, a escola passa a se constituir não somente como um espaço de formação básica ou de valorização cultural, mas principalmente como um local de formação de lideranças comprometidas com a transformação da realidade social em que se encontravam inseridas as comunidades daquela região.

Ainda no que diz respeito aos processos de ressignificação da escola pelos povos indígenas, a professora Mara lembra que, desde a década de 1970, os tuxauas reivindicavam uma escola diferenciada na comunidade, com professores indígenas, em virtude da falta de compromisso dos professores não indígenas. A essa falta de compromisso somou-se a necessidade de formar lideranças para as comunidades e foi, portanto, daí que surgiu a luta para que fosse construída uma escola verdadeiramente indígena.

Além desse processo de formação de lideranças para as comunidades, a professora Mara destacou algumas especificidades que fazem dela uma escola diferenciada. Tais características nos parecem fundamentais para entendermos, não somente os processos de diferenciação das escolas indígenas, mas também a função que elas ocupam dentro das comunidades. Dentre os vários aspectos que poderíamos observar dentro de uma escola como a Dom Lourenço Zoller, a professora destaca o ensino da língua Macuxi, o estudo das leis que amparam os direitos indígenas, a participação dos alunos nas manifestações e lutas das comunidades e o trabalho comunitário.

Atualmente, os professores e comunidade têm plena certeza de que a educação oferecida é 
específica e diferenciada, intercultural e bilíngue e tem como principal objetivo formar lideranças cidadãs, conscientes de suas obrigações, mas acima de tudo, conscientes de seus direitos e deveres. É, portanto, por meio desse modelo educativo que a educação indígena passou a ser escolarizada por um processo de "diálogo de saberes" (Cortés 2011), ou seja, do processo de "interculturalização" (Dietz 2012).

Nesse sentido, as atividades executadas na escola refletem o que a comunidade espera de uma liderança intercultural. Vamos, então, compreender as atividades desenvolvidas nessa escola e o perfil da liderança intercultural almejado por ela.

\section{EDUCAÇÃO ESCOLAR INDÍGENA E FORMAÇÃO DE LIDERANÇAS}

Para compreender o que a comunidade espera de uma liderança intercultural, é preciso estarmos atentos à relação que se estabelece entre educação indígena e educação escolar indígena.

Segundo Brandão (2007), a educação, desde uma perspectiva mais abrangente, existe em todas as sociedades de diferentes maneiras. Dessa forma, a educação indígena pode ser vista como uma fração dos modos de vida dos grupos que criam e recriam, dentre tantas outras invenções de sua cultura, normas, regras e códigos e que são reproduzidos no interior da comunidade. Assim, os saberes que eles produzem atravessam as gerações por meio das palavras da tribo, (a linguagem) dos seus códigos de conduta, bem como dos segredos da religião, da produção do artesanato ou de outra "tecnologia" que cada povo desenvolve para sobreviver.

No entanto, é importante lembrar que durante muito tempo, os povos indígenas foram vistos como “um povo sem educação" (Meliá 1979), por causa do seu modelo de educação ser diferente do modelo ocidental. Nesse sentido, Meliá (1979) nos adverte para o fato de que ao falarmos em educação indígena, devemos levar em consideração que os processos educativos nas sociedades indígenas são extremamente diferentes daqueles compartilhados pela sociedade nacional.

Brandão (2007) chama atenção que, nas sociedades tribais, nem sempre houve uma instituição escolar, no entanto, sempre houve educação e processo educativo. Isso demonstra que a escola não é o único espaço dedicado à aprendizagem, pois podem também serem vistas como situações de aprendizagem aqueles momentos em que as pessoas ou grupos de pessoas trocam bens materiais entre si ou trocam serviços e significados. Ali não há mestres nem inspetores especiais para a juventude, esse papel é desempenhado por todos os anciões da comunidade (Brandão 2007).

É, portanto, partindo desta perspectiva que compreendemos as relações entre educação 
indígena e educação escolar indígena na comunidade Pedra Preta. Apesar de haver uma "imposição normativa" da Secretaria de Estado da Educação de Roraima (SEED), os professores vêm tentando colocar em diálogo esses dois modelos educativos, por meio das práticas culturais, da experiência e da vivência comunitária.

Para realizar esse diálogo de saberes na comunidade, os professores afirmam utilizar, enquanto estratégias metodológicas, a prática de projetos, ancorados em uma proposta "intercultural indutiva”, pelo "calendário sociocultural” (Gashé s.d.). Essa metodologia, segundo eles, possibilita uma interação entre a escola e comunidade, pois, pelo calendário sociocultural, as atividades da comunidade são contempladas no calendário escolar. Assim sendo, a escola se vê obrigada a trabalhar, além dos conteúdos eurocêntricos da matriz curricular, conteúdos da cultura comunitária.

O método indutivo intercultural se constrói a partir da observação das práticas socioculturais da comunidade. Os professores, a partir de suas experiências, registram as práticas da comunidade e as classificam a partir de indicadores astronômicos, biológicos, climatológicos, geológicos, sociais, religiosos etc. A partir dessa classificação, elabora-se o calendário das atividades que serão desenvolvidas, determinando os períodos em que ocorre cada evento. Aqui é importante ressaltar que, no processo de construção desse calendário sociocultural, a participação da comunidade é de fundamental importância, tanto na elaboração do planejamento quanto na sua execução.

A partir das práticas culturais que vêm sendo desenvolvidas na comunidade, os professores da Escola Dom Lourenço Zoller elaboraram os seguintes projetos: Revitalização da Língua, Roça Comunitária, Horta Alimentar, Horta Medicinal, Meio Ambiente, Criança Feliz e Sexta Cultural. Além deles, há ainda outras atividades, como a coleta da saúva, desenvolvidas na comunidade e que fazem parte de suas práticas culturais, mas não estão sistematizadas enquanto projetos.

O projeto Revitalização da Língua consiste na tentativa de fazer com que todos os membros da comunidade voltem a falar em seu próprio idioma. Para tanto, os pais são orientados a se comunicar com seus filhos somente em sua própria língua, ainda que não a compreendam bem. No dia a dia da comunidade, todos os adultos, a começar pelos professores, devem ao menos aprender as saudações mais simples e praticá-las.

Já o projeto Roça Comunitária surgiu a partir da exigência dos pais, por acreditarem que a escola estava tomando o tempo que deveria ser destinado ao trabalho na roça. Hoje, ele se constitui como uma atividade coletiva da 
escola e da comunidade, e tem como principal objetivo a formação dos estudantes e o estímulo às práticas de fortalecimento da produção, por meio da valorização e manutenção das sementes tradicionais que ainda são conservadas pelas famílias da comunidade.

O projeto ainda visa a melhoria do sistema de alimentação da comunidade e, principalmente, em suprir a necessidade da escola com relação à merenda para os alunos, uma vez que ela é fornecida pelo Governo do Estado e dificilmente chega à comunidade. Dessa forma, o Roça Comunitária visa subsidiar a alimentação para as crianças da comunidade em idade escolar, proporcionando assim uma merenda mais saudável. Segundo o professor responsável pelo projeto, ele pode ser visto como "uma atividade coletiva, sendo também uma atividade social, econômica e cultural da comunidade".

É importante lembrar que nos dias de ajuri ${ }^{8}$, não há aulas na escola, mas na própria roça. Ali, os mais velhos, dão aulas para jovens e crianças, sobre a terra, os alimentos, bem como sobre o quê, como e quando plantar. Essa atividade está intimamente ligada às questões climatológicas e astronômicas, pois na sabedoria indígena, as fases da lua influenciam profundamente nas plantações.

O Horta Alimentar já vem sendo desenvolvido pela escola há algum tempo. De acordo com o professor responsável, a horta, assim como a roça, tem como objetivo melhorar a composição nutricional dos alunos e da comunidade. Segundo o docente, nos últimos anos, a alimentação da comunidade está passando por grandes mudanças por causa da entrada de muitos produtos industrializados. Com esses novos produtos na comunidade, muitos dos que ali vivem estavam substituindo as práticas alimentares tradicionais. No entanto, a introdução desses novos costumes estava trazendo prejuízos para a comunidade, pois com eles vieram também algumas doenças que antes não eram conhecidas.

Frente a essa realidade, a escola tomou a iniciativa de desenvolver um projeto com o intuito de incentivar a produção de hortaliças e legumes para melhorar os hábitos alimentares da comunidade, visando ainda a recuperação da produção de algumas plantas que já eram cultivadas na comunidade e propondo a introdução de outras espécies vegetais, que não são da região, mas que trazem benefícios para a saúde das pessoas. $\mathrm{O}$ intuito foi promover uma mudança nos hábitos alimentares da população da comunidade, incentivando-as a consumir alimentos mais saudáveis e produzidos no próprio local ao invés de produtos industrializados.

8 Todo o trabalho realizado coletivamente na comunidade. 
Diferentemente dos outros projetos que são realizados uma ou duas vezes por semana, o trabalho na horta é diário e, por requerer maiores cuidados, vem sendo realizado nas proximidades da comunidade. Para isso, os alunos foram divididos em equipes que se revezam em sua execução. Essa dinâmica foi adotada devido à necessidade de regar as plantações duas vezes por dia. Assim sendo, uma equipe trabalha das $6 \mathrm{~h} 30$ às $7 \mathrm{~h}$, e outra equipe no horário da tarde, começando a partir das $17 \mathrm{~h}$. Essa dinâmica de trabalho adotada pela escola nas práticas de projetos é sempre debatida nas reuniões comunitárias e como a prática de projetos é uma disciplina regular do currículo da escola, não há qualquer rejeição na realização dessas atividades por parte dos alunos. Muitos preferem as aulas de práticas de projetos à sala de aula.

O projeto Educação Ambiental ${ }^{9}$ também nasceu de uma necessidade da comunidade e da própria escola. Segundo o responsável, professor Odivilson, quando ele chegou à comunidade, em 2012, o projeto já existia, porém de forma prática, ou seja, havia a ação, mas não havia um cronograma definido de execução. Ele, então, tomou a iniciativa de elaborar uma proposta mais sistematizada que pudesse respaldar o trabalho da escola frente à comunidade e principalmente frente à SEED. O projeto tem como principal preocupação a destinação do lixo que vem sendo produzido pela comunidade. A preocupação da escola está em encontrar um meio que possa amenizar a produção de resíduos sólidos e, principalmente, encontrar um lugar adequado à destinação deles diante do aumento do consumo de produtos industrializados.

Segundo o professor, sua metodologia consiste na divisão em pequenos grupos para visitas às famílias. Nessas visitas, as famílias são orientadas em relação ao material orgânico e não orgânico para que possam fazer uma separação desse material. Nesse sentido, orienta-se enterrar o material orgânico para seu posterior uso como adubo, e que os demais resíduos sejam depositados em sacos de fibras para serem recolhidos posteriormente. Ainda como metodologia de trabalho, foi estabelecido que os grupos de alunos passariam duas vezes por semana, aproveitando o horário da educação física e da prática de projetos, para fazer a coleta do lixo produzido pela comunidade.

Outro projeto é o Horta Medicinal: cuidando da nossa saúde e valorizando nossa cultura, surgido

9 Este projeto é hoje uma prática cotidiana da comunidade, não é apenas um experimento, mas uma ação contínua da comunidade. Segundo o professor responsável, ele já foi apresentado como um projeto inovador em alguns eventos científicos, pois o tomou como uma de suas ações, já que é aluno da Licenciatura Intercultural e faz parte do Programa Institucional de Bolsas de Incentivo à Docência (PIBID Diversidade). A atividade também foi apresentada em um intercâmbio realizado na própria comunidade, no período em que estávamos em trabalho de campo, e foi celebrado entre os alunos da Licenciatura Intercultural do Instituto Insikiram e alunos da Licenciatura de Educação do Campo, ambos participantes do PIBID Diversidade. 
da necessidade de melhorar a qualidade de vida e saúde da comunidade e dos estudantes, como afirmou a professora Valdirene, a coordenadora. Segundo ela, o principal objetivo é fortalecer os conhecimentos tradicionais do povo Macuxi pela valorização e uso da medicina tradicional na comunidade. Trata-se, portanto, de um projeto que visa à melhoria da saúde e do bem-estar comunitário. Assim como os demais projetos, ele é executado às quintas-feiras, das $7 \mathrm{~h} 30$ às $11 \mathrm{~h}$, horário destinado às práticas de projetos.

Por se tratar de uma ação que está relacionada diretamente com a saúde da população, ela vem sendo desenvolvida em parceria com os Agentes Indígenas de Saúde (AIS). Dentre as atividades realizadas, a professora destaca a preparação do solo, plantação de mudas e ações no sentido de dar visibilidade ao projeto. É o caso de oficinas na Escola Júlio Pereira, na cidade de Uiramutã, nas quais trabalhou-se a produção de xaropes, garrafadas e pomadas. A professora ressalta que nessa atividade houve a participação tanto dos Agentes Indígenas de Saúde quanto dos alunos.

O projeto Criança Feliz foi uma iniciativa dos professores do $1^{\circ}$ ao $5^{\circ}$ ano (Ensino Fundamental I) que perceberam a necessidade de inserir as crianças no processo de valorização cultural da comunidade. Segundo ele, esse público-alvo não participava das atividades da prática de projetos.
Frente a essa realidade, eles se organizaram, com o apoio da gestão da escola e criaram o projeto. De acordo com uma das professoras, a ideia surgiu da necessidade de fortalecer os valores culturais, que ainda se mantêm vivos na comunidade da Pedra Preta. Segundo ela,

"É uma experiência de como
trabalhar as áreas de conhecimento,
ciências da natureza, ciências sociais,
comunicação e arte, ambiente, saúde
e diversidade cultural através dos
termos contextuais. E tem como
objetivo principal fortalecer o
ensino e a aprendizagem, bem com
contribuir na formação, com um foco
intercultural, visando à valorização
do território, e a construção de um
currículo diferenciado." (Professora
Maria, entrevista realizada em abril
de 2013).

O projeto Sexta Cultural é uma prática que já vem sendo adotada há vários anos, realizada sempre na última sexta-feira do bimestre, como parte do calendário escolar oficial, sendo considerado um dia letivo. Seu objetivo, segundo os professores, além de promover uma maior interação entre a escola e a comunidade, é mostrar à comunidade o trabalho que vem sendo desenvolvido pela instituição. Para tanto, logo no início de cada bimestre, os professores são chamados a planejar suas atividades, quando devem ser incluídas as atividades que serão apresentadas na Sexta Cultural. Ressaltamos que durante nossas estadas na comunidade, pudemos presenciar e participar da realização deste projeto. 
Outras atividades que têm sido muito valorizadas pela escola, como elemento de construção do conhecimento e valorização dos saberes tradicionais, são as atividades de cunho social, por exemplo, as manifestações organizadas pelo movimento indígena. Em tais ações, os alunos são convidados a participar, porque, segundo as lideranças, as manifestações de reivindicação e de lutas são momentos muito importantes, pois ali é contada e recontada a memória do povo.

É importante mencionar que, além do aprendizado sobre a história e os processos de lutas dos seus antepassados, os próprios estudantes defendem que a sua participação os ajuda a se constituírem como futuras lideranças dentro da comunidade, pois quando os mais antigos não estiverem nas comunidades, são eles que tomarão a frente das lutas para que seus direitos, que lhes foram garantidos constitucionalmente, não venham a ser retirados.

Portanto, o processo de formação de lideranças na Escola Dom Lourenço Zoller é realizado pela prática de projeto, da participação nas manifestações do movimento indígena organizado e de outras atividades não contempladas pelos projetos, além dos aprendizados da língua portuguesa e da língua materna. É importante ressaltar que a prática de projetos não está separada das atividades de sala de aula, pois os professores sempre procuram articular o conhecimento prático adquirido com eles ao conhecimento do currículo nacional. Essa metodologia tem, inclusive, despertado cada vez mais o interesse dos alunos pela escola, tanto quanto pelos trabalhos.

O que se vê na Escola Dom Lourenço Zoller é um processo de formação a partir de um diálogo de saberes, ou seja, da interculturalização da educação escolar. Dialogando com os saberes ocidentais e indígenas, a formação realiza práticas interculturais, ao mesmo tempo busca manter a autonomia e autodeterminação para as gerações futuras.

O que se espera de uma liderança indígena na comunidade Pedra Preta é que após seu processo de formação, fique em suas comunidades e seja capaz de desenvolver as práticas que foram aprendidas durante seu processo de formação na escola. Além disso, espera-se que essa nova liderança atue no processo de conscientização de sua comunidade, no sentido de valorizar sua própria cultura e na defesa permanente dos seus direitos, principalmente o direito a terra.

Essa metodologia tem aportado importantes resultados para a comunidade, já que, além de formar as próprias lideranças, forma também lideranças para as comunidades adjacentes. Desse modo, a comunidade é vista atualmente como mais um centro de formação na região das serras. 
A contribuição da Escola Dom Lourenço Zoller e suas formas de trabalho não fica circunscrita somente à região ou aos povos indígenas. Um exemplo disso foi a troca de experiências realizada entre os professores da comunidade (alunos do Instituto Insikiran de Formação de Professores) com os alunos do curso de Educação do Campo da Universidade Federal de Roraima (UFRR) e essa troca de experiências aconteceu na própria comunidade indígena.

Mesmo com todos esses avanços, não podemos pensar que não há problemas na comunidade. Eles existem e são inúmeros, sendo um dos principais a articulação das atividades práticas com as atividades teóricas de sala de aula, além da dificuldade de aceitação de que essas atividades ou mesmo que dias letivos a eles relacionadas sejam contabilizados na escola. O que se percebe no discurso dos professores é que há uma imposição da Secretária de Educação em relação ao currículo e carga horária da escola.

Apesar das dificuldades, os resultados alcançados até o momento têm sido um importante alicerce na organização da comunidade e de suas relações políticas com grupos circunvizinhos e a sociedade nacional. Os processos de imposição são conhecidos pelo grupo e as práticas interculturais têm sido uma resposta efetiva de enfrentamento e de fortalecimento dos direitos indígenas.

\section{CONSIDERAÇÕES FINAIS}

Ao refletirmos sobre a educação escolar na comunidade Pedra Preta foi possível perceber que ela pode ser vista e analisada em duas fases. A primeira inicia-se com a introdução da escola na comunidade nos anos 1970 e vai até o ano de 1994. Nessa primeira fase, a Escola Dom Lourenço Zoller estava orientada por uma pedagogia tradicional e tinha como objetivo ensinar os jovens indígenas a ler e a escrever, já que foi introduzida na comunidade com o objetivo de dotar os jovens e crianças indígenas de conhecimentos técnicos científicos, a fim de prepará-los para enfrentar garimpeiros e fazendeiros em pé de igualdade, mas não conseguia atingir seus objetivos com sucesso por causa do uso da pedagogia homogeneizante e da ausência de professores.

Em 1994, a escola passa por um processo de ressignificação e introduz na comunidade uma política educativa voltada à valorização de diferentes aspectos da cultura Macuxi. Nos primeiros anos de trabalho por essa perspectiva, ela limitou-se a trabalhar a questão dos cantos na língua indígena e a dança do parixara.

A partir do ano de 1998, o trabalho em busca de uma educação diferenciada começa a ser mais efetivo, com destaque para formação de lideranças. A partir de então, os professores e a comunidade passaram a lutar pela consolidação de uma 
educação específica e diferenciada, intercultural e bilíngue. $\mathrm{O}$ apoio da comunidade e as práticas de projetos têm sido o meio para a efetivação desse modelo educativo.

No entanto, esse trabalho ainda vem encontrando algumas barreiras dentro e fora da comunidade, pois alguns pais não estão de acordo com essa nova proposta educativa que a escola vem desenvolvendo. Para eles, ela deveria limitar-se a ensinar a ler a escrever, ou seja, formar os alunos nos moldes das escolas urbanas, para que, quando eles saírem da comunidade, estejam preparados para competir em pé de igualdade por empregos na cidade. Por outro lado, a própria Secretaria de Estado da Educação ainda reluta em reconhecer as atividades práticas da comunidade como um componente curricular. Entendemos que tal relutância está relacionada a um processo de hierarquização dos saberes. Portanto, esse é o grande desafio dos professores.

Ao refletir sobre as especificidades da escola, os professores também foram enfáticos em colocar o ensino da língua materna e a prática de projetos como elementos definidores de sua distinção. O ensino multilíngue, tal como é defendido por eles, tem como objetivo a valorização e a manutenção da língua nativa. Já a prática de projetos, além de buscar uma interação entre a teoria e prática, é vista como uma forma de fortalecer práticas culturais que vinham sendo esquecidas.

Com relação à interculturalidade e educação intercultural, os professores afirmam que é um debate tratado com toda a comunidade. Hoje, a escola vem trabalhando uma educação intercultural, sendo vista como uma forma de diálogo entre culturas e, principalmente, como um diálogo de saberes entre pessoas portadoras de culturas distintas.

Algumas questões merecem ainda ser destacadas ao tentarmos compreender como tem se dado esse diálogo. A realização de projetos, tal como acontece na escola em questão, parece não se diferenciar de propostas conhecidas em escolas não indígenas. No entanto, destacamos a compreensão do tempo, dos ciclos de produção, da preparação de lideranças, dos direitos e cidadania e do reconhecimento de outros detentores de saber que não apenas os professores, tudo mediado pela diversidade linguística, como os elementos que vão possibilitar aos indígenas que ali estudam desenvolverem a consciência de onde e como estão situados em relação ao mundo, à sociedade envolvente e também ao Estado. São esses os elementos que situam cosmologias nos campos intersocietários em que se insere a Escola Dom Lourenço Zoller e que permitem encontrarmos, no caso relatado, um caminho para o diálogo intercultural. 
A formação de lideranças interculturais tem sido um importante alicerce para o diálogo entre os saberes ocidental e indígena, bem como para o enfrentamento das imposições da sociedade nacional e defesa dos direitos indígenas, principalmente aqueles relacionados à preservação da propriedade comunitária da terra.

\section{REFERÊNCIAS}

Barth, Fredrik. 2000. O guru, o iniciador e outras variações antropológicas. Rio de Janeiro: Contra Capa Livraria.

Brandão, Carlos Rodrigues. 2007. O que é educação? São Paulo: Brasiliense.

Brasil. Secretaria de Educação Fundamental. 1998. Referencial Curricular Nacional para Escolas Indígenas. Brasília: Ministério da Educação e do Desporto.

Cohn, Clarice. 2005. Educação escolar indígena: por uma discussão de cultura, criança e cidadania ativa. Perspectiva. 23 (2):485-515.

Dietz, Gunther. 2012. Multiculturalismo, interculturalidad y diversidad en educación: Una aproximación antropológica. Cidade do México: FCE.

Mateos Cortés, Laura Selene. 2011. La migración transcultural del discurso intercultural: su incorporación, apropiación y resignificación por actores educativos en Veracruz, México. Quito: Ediciones Abya-Yala.

Meliá, Bartomeu. 1979. Educação indígena e alfabetização. São Paulo: Edições Loyola.

Melo, Maria Auxiliadora de Souza. 2000. Metamorfose do saber Macuxi/Wapichana: Memoria e Identidade. Dissertação de mestrado, Programa de Pós-Graduação em Educação, Universidade Federal do Amazonas, Manaus.

Nascimento, Raimundo Nonato F. 2014. Interculturalidade e educação escolar indígena em Roraima: da normatização à prática cotidiana. Tese de doutorado, Programa de Pós-graduação em Antropologia da Universidade Federal de Pernambuco, Recife. 
Paladino, Mariana. 2001. Educação escolar indígena no Brasil contemporâneo: entre a revitalização cultural e a desintegração do modo de ser tradicional. Dissertação de mestrado, Programa de Pósgraduação em Antropologia Social, Museu Nacional, Rio de Janeiro.

Rebolledo, Nicanor. 2009. Cultura, escolarización y etnografia. Los plikur en el Amazonas brasileño del Bajo Uaça. Cidade do México: Universidad Iberoamericana.

Silva, Aracy Lopes da. 2001. A educação indígena entre diálogos interculturais e multidisciplinares: introdução, in Antropologia, História e Educação: a questão indígena na escola. Organizado por Silva, Aracy Lopes da e Ferreira, Mariana, pp. 9-25. São Paulo: Global.

Torres, Maristela Sousa. 2007. Interculturalidade e educação: um olhar sobre as relações interétnicas entre alunos Iny e a comunidade escolar da região do Araguaia. Cuiabá: EdUFM.

Tassinari, Antonella. 2001. Escola Indígena: novos horizontes teóricos, novas fronteiras da educação. Organizado por Silva, Aracy Lopes da e Ferreira, Mariana, pp. 44-70. São Paulo: Global. 
